\title{
Clonal Hematopoiesis and Premalignant Diseases
}

\author{
Justin Kaner, ${ }^{1}$ Pinkal Desai, ${ }^{1}$ Nuria Mencia-Trinchant, ${ }^{1}$ Monica L. Guzman, ${ }^{1}$ Gail J. Roboz, ${ }^{1}$ \\ and Duane C. Hassane ${ }^{1,2}$ \\ ${ }^{1}$ Division of Hematology \& Oncology, Weill Cornell Medical College, New York, New York 10065, USA \\ ${ }^{2}$ Caryl and Israel Englander Institute for Precision Medicine, Weill Cornell Medical College, New York, \\ New York 10065, USA \\ Correspondence: dhassane@med.cornell.edu
}

Clonal hematopoiesis $(\mathrm{CH})$ arises when mutations in the hematopoietic system confer a fitness advantage to specific clones, thereby favoring their disproportionate growth. The presence of $\mathrm{CH}$ increases with age and environmental exposures such as cytotoxic chemotherapy or radiotherapy. The most frequent mutations occur in epigenetic regulators, such as $D N M T 3 A, T E T 2$, and $A S X L 1$, leading to dysregulation of tumor suppressor function, pathogen response, and inflammation. These dysregulated processes elevate risk of overall mortality, cardiovascular disease, and eventual hematologic malignancy $(\mathrm{HM})$. $\mathrm{CH}$ is likely acting as an initiating event leading to HM when followed by cooperating mutations. However, further evidence suggests that $\mathrm{CH}$ exerts a bystander influence through its pro-inflammatory properties. Delineating the mechanisms that lead to the onset and expansion of $\mathrm{CH}$ as well as its contribution to risk of $\mathrm{HM}$ is crucial to defining a management and intervention strategy. In this review, we discuss the potential causes, consequences, technical considerations, and possible management strategies for $\mathrm{CH}$ in the context of $\mathrm{HMs}$ and pre-HMs.

$T^{\mathrm{h}}$ he accumulation of mutations in overtly healthy tissues occurs during normal aging with somatic mosaicism being present from birth (Vilkki et al. 2001; De 2011; Blokzijl et al. 2016; Vattathil and Scheet 2016). Although the majority of these mutations are neutral and do not favor clonal expansion (Martincorena et al. 2017), mutation-driven dominant clones have been observed in nearly all tissues, especially in the hematopoietic system (Bowman et al. 2018). Hematopoietic stem cells (HSCs) initiate hematopoietic development and only seldomly enter into the cell cycle for self-renewal and replication (Catlin et al. 2011), with each HSC acquiring approximately one exonic somatic mutation per decade in a largely stochastic manner (Welch et al. 2012). A subset of these acquired mutations confers a growth advantage (Welch et al. 2012), producing a clonal expansion that has been termed "clonal hematopoiesis" $(\mathrm{CH})$.

Although the genes most commonly mutated in $\mathrm{CH}$ are the same genes that drive malignant conditions like myelodysplastic syndrome (MDS) and acute myeloid leukemia (AML),

Editors: Michael G. Kharas, Ross L. Levine, and Ari M. Melnick

Additional Perspectives on Leukemia and Lymphoma: Molecular and Therapeutic Insights available at

www.perspectivesinmedicine.org

Copyright (C) 2020 Cold Spring Harbor Laboratory Press; all rights reserved; doi: 10.1101/cshperspect.a035675

Cite this article as Cold Spring Harb Perspect Med 2020;10:a035675 
J. Kaner et al.

most persons with $\mathrm{CH}$ are overtly healthy and never progress to MDS/AML. Nonetheless, $\mathrm{CH}$ is not an inert condition. $\mathrm{CH}$ clones have been known to show elevated inflammation, impaired tumor suppressor function, risk of cardiovascular disease (CVD), and risk of eventual hematologic malignancy (HM) (Jaiswal et al. 2014; Xie et al. 2014; Genovese et al. 2015; Rasmussen et al. 2015; Wu et al. 2015). Indeed, $\mathrm{CH}$ confers a rate of progression to any $\mathrm{HM}$ of $0.5 \%-1 \%$ per year (Jaiswal et al. 2014). This rate of progression is similar to monoclonal gammopathy of undetermined significance (MGUS) and monoclonal B-cell lymphocytosis (MBL) with the notable exception that $\mathrm{CH}$ can potentially produce any $\mathrm{HM}$ as it can arise in less committed hematopoietic precursors. Recent case-control studies have sought to fine-tune this risk especially in AML (Abelson et al. 2018; Desai et al. 2018). Nonetheless, the certainty of progression to any one condition in any single person is still not absolute given the presence of $\mathrm{CH}$, mutation pattern, and/or any given clinical parameter. Data in model systems have shown that the growth and oncogenic progression of $\mathrm{CH}$ mutations may be influenced by extrinsic factors, varying from microbial and inflammatory signals to vitamin C (Cimmino et al. 2017; Cai et al. 2018; Meisel et al. 2018). Thus, the contribution of $\mathrm{CH}$ to disease is likely to involve a complex interplay between stochastic molecular events and their interaction with an individual's "exposome" (Wild 2005). Understanding $\mathrm{CH}$ mutations in the context of these extrinsic influences will enable development of better predictive models to improve decision-making when $\mathrm{CH}$ is detected. Although the cardiovascular risks associated with $\mathrm{CH}$ are important and considerable, the present review will focus on presenting what is known about the genetics, risks, and effects of $\mathrm{CH}$ in regard to premalignant conditions and hematologic malignancies.

\section{CLONAL HEMATOPOIESIS}

$\mathrm{CH}$ is functionally defined by the disproportionate growth of hematopoietic clones harboring a common somatic alteration. The first description of $\mathrm{CH}$ arose from excess skewing of the
1:1 ratio of maternal to paternal $\mathrm{X}$-inactivation normally observed in women by Gale in 1991 (Lyon 1961; Gale et al. 1991). Subsequent advances in molecular techniques enabled Busque and colleagues, in 1996, to make quantitative assessments showing that neonates and young women had significantly less X-inactivation skewing than women $>60 \mathrm{yr}$ old, suggesting that $\mathrm{CH}$ is an age-related phenomenon (Busque et al. 1996). Follow-up studies revealed that somatic mutations are the probable underlying drivers of $\mathrm{CH}$ with the finding that elderly women with nonrandom $\mathrm{X}$-inactivation were significantly more likely to harbor TET2 mutations (Busque et al. 2012), which until then had been principally described as a driver event in AML causing epigenetic dysregulation (Delhommeau et al. 2009; Chou et al. 2011; Moran-Crusio et al. 2011). Individuals with $\mathrm{CH}$ typically have hematologic parameters that are indistinguishable from normal individuals inclusive of white blood cell count, hemoglobin, red cell distribution width (RDW), and platelets. Notably, the presence of both $\mathrm{CH}$ and high RDW synergizes so as to worsen outcomes (Jaiswal et al. 2014). Many groups have shown RDW to be a poor prognostic factor in a variety of settings, suggesting it to be a marker of chronic disease (Baba et al. 2018; Zurauskaite et al. 2018).

\section{MUTATION LANDSCAPE OF CLONAL HEMATOPOIESIS}

The most common mutations driving $\mathrm{CH}$ occur in the epigenetic modifier genes DNMT3A, TET2, and ASXL1 (Jaiswal et al. 2014; Xie et al. 2014; Genovese et al. 2015; Steensma et al. 2015). The prevalence of DNMT3A mutations is highest, representing $\sim 45 \%$ of all $\mathrm{CH}$ mutations. Mutations in TET2 and ASXL1 also occur commonly but each represent only $10 \%$ or less of all $\mathrm{CH}$ mutations (Heuser et al. 2016), although variable coverage of these large tumor suppressor genes on exome/panel-based sequencing suggests the actual mutation frequency may vary in different cohorts. Other less frequent somatic mutations have been shown to occur in TP53, PPM1D, JAK2, CBL, and spliceosome genes (Jaiswal et al. 2014; Xie et al. 2014; Geno- 
vese et al. 2015; Steensma et al. 2015; Coombs et al. 2017). Although the genes most commonly mutated in $\mathrm{CH}$ are the same genes that drive malignant conditions like MDS and AML, most persons with $\mathrm{CH}$ never progress to MDS/ AML and otherwise show normal hematologic parameters. These same genes commonly mutated in $\mathrm{CH}$ occur as a function of age both in $\mathrm{CH}$ (Jaiswal et al. 2014; Genovese et al. 2015) and in overt myeloid neoplasms such as MDS, myeloproliferative neoplasms (MPNs), and AML. Nonetheless, $\mathrm{CH}$ is not an inert condition. $\mathrm{CH}$ clones have been known to show elevated inflammation, impaired tumor suppressor function, risk of CVD, and risk of eventual HM (Jaiswal et al. 2014; Genovese et al. 2015). Indeed, $\mathrm{CH}$ confers a rate of progression to any HM of $0.5 \%-1 \%$ per year (Jaiswal et al. 2014). This rate of progression is similar to MGUS and $\mathrm{MBL}$, with the notable exception that $\mathrm{CH}$ can potentially increase risk of any HM as it arises in less-committed hematopoietic precursors. Recent case-control studies have sought to define this risk especially in AML (Abelson et al. 2018; Desai et al. 2018). Nonetheless, the certainty of progression to any one condition in any single person is still not absolute. Data in model systems have shown that the growth and oncogenic penetrance of $\mathrm{CH}$ mutations may be influenced by extrinsic factors, such as microbial and inflammatory signals, and nutritional factors like vitamin C (Cimmino et al. 2017; Cai et al. 2018; Meisel et al. 2018). Thus, the contribution of $\mathrm{CH}$ to disease is likely to involve a complex interplay between stochastic molecular events and their interaction with an individual's "exposome" (Wild 2005). Understanding CH mutations in the context of these extrinsic influences will enable development of better predictive models to improve decision-making when $\mathrm{CH}$ is detected. Although the cardiovascular risks associated with $\mathrm{CH}$ are important and considerable and reviewed elsewhere (Sano et al. 2018; Calvillo-Argüelles et al. 2019), the present review will focus on presenting what is known about the genetics, risks, and possible management strategies for $\mathrm{CH}$ in the context of premalignant conditions and hematologic malignancies (Fig. 1).

\section{CLONAL HEMATOPOIESIS ELEVATES RISK OF PROGRESSION TO HEMATOLOGIC MALIGNANCIES}

Premalignant states are well-established in hematologic malignancies, including $\mathrm{MBL}$ as a precursor to chronic lymphocytic leukemia (CLL) and MGUS as a precursor to multiple myeloma (MM), progressing to full disease at a rate of $1 \%$ to $2 \%$ per year (Kyle et al. 2002; Rawstron et al. 2008). Certain higher-risk presentations of $\mathrm{CH}$ can confer similar rates of disease progression. Indeed, Jaiswal and colleagues tested for $\mathrm{CH}$ across genes recurrently mutated in myeloid and lymphoid malignancies in the peripheral blood of 17,182 individuals via whole-exome sequencing (WES) at $70 \times$ median coverage depth (Jaiswal et al. 2014). Using variant allele fraction (VAF) cutoffs of $3.5 \%$ of singlenucleotide variants (SNVs) and 7\% for indels, the prevalence of $\mathrm{CH}$ increased in an age-dependent manner from $2.5 \%$ in the $50-59$ age group to $9.5 \%$ in the $70-79$ age group. The presence of $\mathrm{CH}$ in any driver gene increased the risk of HM by $>11$-fold (hazard ratio [HR]: $11.1,95 \%$ confidence interval [CI] 3.9-33). A large clone size (VAF $>10 \%$ ) further elevated this risk to 49 -fold (HR: 49, 95\% CI: 21-120). Although the fold change in HM risk is high based on these data, the absolute risk is relatively low with only $4 \%$ of individuals with a $\mathrm{CH}$ mutation progressing to develop a HM during the study period of 95 mo corresponding to $0.5 \%$ per year overall in the presence of any $\mathrm{CH}$. Large clone size (VAF > $10 \%$ ) elevated the progression rate to $1.0 \%$ per year, approaching progression rates similar to MBL or MGUS. All-cause mortality associated with RDW from 1.6 (95\% CI: 1.2-2.1) in the absence of $\mathrm{CH}$ to 3.7 (95\% CI: 2.2-6.5) in the presence of $\mathrm{CH}$ when $\mathrm{RDW} \geq 14.5 \%$. Similar contemporaneous studies arrived at similar conclusions with regard to risk of progression to HR and rates of elevated CH (Xie et al. 2014; Genovese et al. 2015).

\section{TECHNICAL DEFINITION OF CLONAL HEMATOPOIESIS}

Uniform standards for the detection and reporting of $\mathrm{CH}$ are absent and urgently needed. Tech- 
J. Kaner et al.

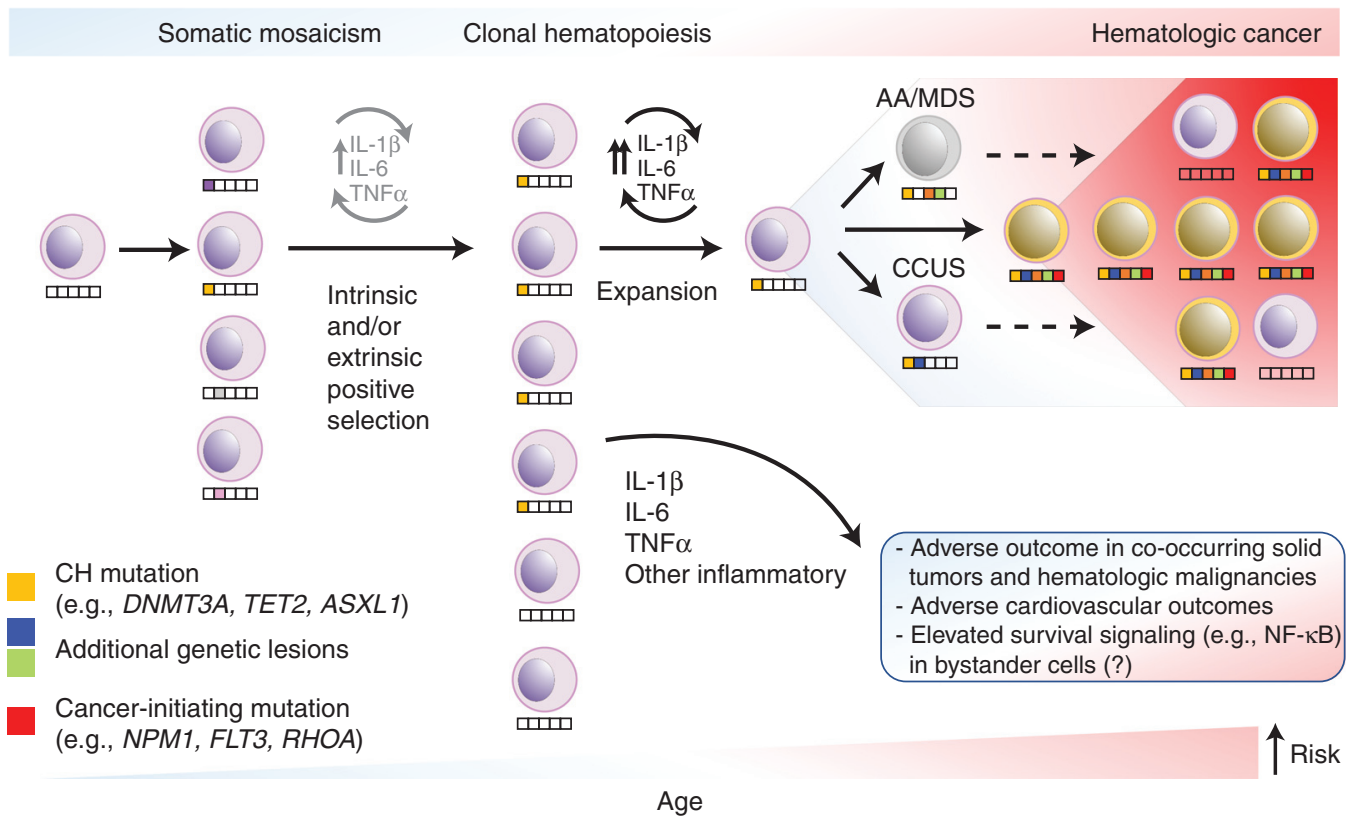

Figure 1. Progression from somatic mosaicism through clonal hematopoiesis $(\mathrm{CH})$ into hematologic malignancy. A combination of intrinsic and/or extrinsic events favors expansion of hematopoietic cells harboring mutations that confer a fitness advantage (e.g., mutations DNMT3A, TET2, and ASXL1) leading to CH. CH is pro-inflammatory and produces a positive-feedback loop that produces conditions favorable for the $\mathrm{CH}$ clone's expansion (i.e., its own expansion). Acquisition of subsequent mutations leads to clonal cytopenia of uncertain significance (CCUS), aplastic anemia (AA), or myelodysplastic syndrome (MDS), and other overt hematologic malignancies (e.g., acute myeloid leukemia). Aberrant pro-inflammatory signals also potentially exert a bystander influence on neighboring non-CH cells, thereby favoring adverse outcomes in co-occurring cancers and cardiovascular disease. It is speculated here that the pro-inflammatory environment generated by $\mathrm{CH}$ may promote protective survival signaling through pathways such as nuclear factor kappa B (NF- $\mathrm{kB}$ ). The colored squares under each cell depict indicate somatic mutations. $\mathrm{CH}$ mutations are early events and followed by additional genetic lesions, including cooperating cancer mutations. Age increases risk of $\mathrm{CH}$ and hematologic malignancies.

nical variations such as read depth, VAF cutoffs, germline variant exclusion criteria, and the breadth of genes interrogated have complicated the comparison of $\mathrm{CH}$ rates across cohorts. For example, deep targeted error-corrected sequencing revealed that mutations can be identified in the blood of nearly all persons aged 50-70 at a sensitivity of $0.03 \%$ VAF (Young et al. 2016). Although somatic mosaicism in hematopoietic cells is common, the mutations that confer a selective advantage are likely to be most important to the relevance of $\mathrm{CH}$ as a clinical condition. To this end, Steensma and colleagues proposed a VAF of $>2 \%$ in defining $\mathrm{CH}$ (Steensma et al. 2015). This cutoff, however, is driven by available technological capacity and limited clinical data. Recent studies have shown elevated risk even at $>1 \%$ VAF for certain mutation classes (Abelson et al. 2018; Desai et al. 2018). Studies that are scientifically, statistically, and clinically principled are required to establish more formal thresholds.

Overall, the true prevalence of $\mathrm{CH}$ is likely underestimated in most studies. For example, whole-exome studies performed at $70 \times-80 \times$ median depth of coverage will only achieve $<5 \%$ sensitivity for mutations occurring at $2 \%$ VAF based on next-generation sequencing (NGS) sensitivity estimates modeled by Shin et al. (2017), thereby missing the vast majority of $\mathrm{CH}$ mutations at lower VAF. Earlier wholeexome studies (Jaiswal et al. 2014; Genovese 
et al. 2015) were also lacking coverage for most coding exons for TET2 (Genovese et al. 2014; Jaiswal et al. 2014). There is, moreover, an ascertainment bias in the selection of genetic events driving $\mathrm{CH}$ in which studies have generally examined small variants related to progression to HM. In an analysis of 11,000 adults of all ages, whole-genome sequencing (WGS) studies by Zink et al. (2017), searching for mutations in candidate and noncandidate driver genes, yielded a significantly higher prevalence of $\mathrm{CH}$ than what had previously been reported (Jaiswal et al. 2014; Genovese et al. 2015; Zink et al. 2017). With the inclusion of both leukemia driver mutations and nondriver mutations, $\sim 50 \%$ of those 85 and older had evidence of $\mathrm{CH}$ in this cohort, compared with $\sim 20 \%$ in data from other studies (Jaiswal et al. 2014; Genovese et al. 2015; Zink et al. 2017). More recently, Loh and colleagues showed clonal expansions in which $\mathrm{CH}$ is defined by larger-scale mosaic chromosomal alterations (Loh et al. 2018). As consensus forms and depth, uniformity, and breadth of coverage are standardized, the actual prevalence is likely $>20 \%-30 \%$ in persons 50 years of age and above based on two recent high-depth studies (Abelson et al. 2018; Desai et al. 2018) as well as data from blood of solid tumor patients derived from MSK-IMPACT (Coombs et al. 2017).

Finally, different terminologies are currently being used to describe similar states of clonal expansion in the absence of cytopenia or dysplastic hematopoiesis. $\mathrm{CH}$ and "clonal hematopoiesis of indeterminate potential" (CHIP) roughly refer to the same hematologic process with differing levels of specificity (Bowman et al. 2018). CH has a broader definition as it is inclusive of any disruptive somatic event that attains a fitness advantage exceeding the background level of somatic mosaicism-not necessarily occurring in a HM-associated driver such as DNA structural abnormalities or skewed X-inactivation. The term age-related clonal hematopoiesis (ARCH) emphasizes the age association with the acquisition of such mutations but would seem to exclude $\mathrm{CH}$ mutations driven by therapy. In reality, although age is a principle driver, the events driving the expansion of $\mathrm{CH}$ clones are unknown in many cases and may arise from prior therapy, chemical, immunological, infectious, and age-related events that initiate and/or select particular clones.

\section{CCUS AND ICUS}

Idiopathic cytopenia of undetermined significance (ICUS) was proposed as a classification in 2005 and was defined as persistent cytopenias without evidence of dysplasia in the bone marrow and with normal cytogenetics, in the absence of any secondary cause (Wimazal et al. 2007). The largest study to date on patients determined to meet strict criteria for ICUS showed this entity to be quite rare (10 of 2899 patients over $12 \mathrm{yr}$ ) but evolution to MDS was common $(6 / 10)$ and thus supports the hypothesis that this might actually represent a pre-MDS clinical phase (Steensma 2012). With better diagnostic tools incorporating standard karyotypic and targeted sequencing analyses, diagnosing MDS has become significantly more streamlined (Steensma et al. 2015). There remain, however, large portions of individuals with persistent cytopenias and somatic mutations in the absence of overt dysplasia. These instances of normal marrow morphology, but persistent cytopenias in the presence of somatic mutations, underscore our need for a more inclusive classification system (Jaiswal et al. 2014; Genovese et al. 2015; Steensma et al. 2015). When the term ICUS was derived, the ability to universally sequence patient samples was lacking, and thus it was unclear if this was a clonal process. Although many of the patients in the limited analysis above did eventually develop MDS, it remains unclear whether any of these patients had or developed somatic mutations. In an analysis of a clinical cohort of patients who met criteria for ICUS, between $21 \%$ and $33 \%$ had $\mathrm{CH}$-associated mutations, and this prevalence was higher than the background rate of $\mathrm{CH}$ in an age-matched population (Hall et al. 2014; Kwok et al. 2014). In addition, these clonal cytopenias have a similar prevalence as MDS (Steensma et al. 2015). Yet, it should also be noted that progression of these clonal cytopenias to MDS is not universal, and so they remain distinct entities. Given our better understanding of ICUS and $\mathrm{CH}$, it was proposed 
J. Kaner et al.

that we classify patients meeting criteria for ICUS and harboring $\mathrm{CH}$-associated somatic mutation as CCUS. These entities exist on a spectrum with nonclonal ICUS having a very low progression risk and CCUS having a still low but increased risk of progression to MDS (Steensma et al. 2015).

\section{CLONAL HEMATOPOIESIS IN APLASTIC ANEMIA}

$\mathrm{CH}$ is a common finding in individuals with aplastic anemia (AA). In a study of 439 patients with AA undergoing immunosuppressive therapy (IST), 47\% of patients showed evidence of $\mathrm{CH}$ (Yoshizato et al. 2015). Unlike $\mathrm{CH}$ in the general population, the predominant mutations were $B C O R / B C O R L 1, P I G A, D N M T 3 A$, and ASXL1, accounting for $>75 \%$ of $\mathrm{CH}$. Mutations in TET2 were notably underrepresented. Selection pressure in the context of bone marrow failure thus favor patterns of clonal dominance that differ from age-related $\mathrm{CH}$. The prognostic impact in AA varied dependent on the mutation with PIGA, BCOR, and BCORL1 mutations predicting better improved overall survival (OS) and progression-free survival (PFS) with immunosuppressive therapy being compared than TP53, DNMT3A, JAK2, and ASXL1, showing improved OS (HR: 0.27, 0.09-0.78; $P=0.016$ ). PIGA and BCOR/BCORL1 mutations showed clonal attrition over time while DNMT3A and ASXL1 mutations expanded. Despite mutational commonalities with MDS (e.g., DNMT3A, ASXL1, RUNX1, splicing), the average clone size of $\mathrm{CH}$ in the AA cohort was lower $(<10 \%$ VAF) and the clone size substantially rapidly expanded 6 mo post-IST.

Overall, the heightened prevalence of $\mathrm{CH}$ mutations that are found in the general population among patients in premalignant states or smoldering disease suggests their causal influence in the stepwise progression to overt leukemias. These findings thus suggest the usage of mutation screening in identifying at-risk persons and, given the high prevalence of $\mathrm{CH}$ in the general population, the importance of identifying better methods of predicting who will progress to overt leukemia.

\section{FOUNDER CLONAL HEMATOPOIESIS: KNUDSONIAN PROGRESSION TO LEUKEMIA}

Genetics of cancer development are largely modeled around the Knudson "two-hit hypothesis" (Knudson 1971), and the available data suggest that this principle can govern progression from $\mathrm{CH}$ to overt leukemia. Accordingly, mutation of epigenetic regulators, such as DNMT3A, TET2, or ASXL1, commonly seen in $\mathrm{CH}$, represent an initial "hit." The ensuing epigenetic remodeling leads to premalignant changes-for example, reduced GATA2 function leading to impaired differentiation (Madzo et al. 2014; Shih et al. 2015). A subsequent "second hit" promotes progression to overt malignancy. For example, a second-hit mutation in NPM1 produces AML whereas a second-hit mutation in RHOA produces angioimmunoblastic T-cell lymphoma (AITL) (Tiacci et al. 2018). Thus, founder $\mathrm{CH}$ mutations show multilineage oncogenic potential that is determined, at least partly, by subsequent oncogenic mutations.

Recent studies from Jan and colleagues and Shlush and colleagues have delineated the clonal trajectory from the early $\mathrm{CH}$-like mutations to overt AML through sequencing of preleukemic stem and progenitor cells (pre-LSCs) (Jan et al. 2012; Shlush et al. 2014). Through single-cell sequencing, Jan and colleagues described a stepwise accumulation of mutations arising initially in pre-LSCs but eventually developing into LSCs and overt AML on acquisition of secondary mutations (FLT3-ITD). FLT3-ITD was not present in any of the pre-LSCs with several mutations, including SMC1A, and TET2 only present in the pre-LSCs. Similarly, Shlush and colleagues analyzed highly purified HSCs, with progenitor and mature cell fractions from the blood of AML patient fractions and using deep targeted sequencing with a read depth of $\sim 250 \times$, found recurrent DNMT3A mutations at high allele frequency but without the co-occurring NPM1 mutations found in the AML blasts. Consistent with $\mathrm{CH}$ and previous mouse model data (Jan et al. 2012; Kim et al. 2013), these DNMT3A mutated pre-LSCs showed a self-renewal advantage over nonmutated HSCs in xenografts. 
These data together provided support for the presence of pre-LSCs. Further analysis revealed these pre-LSCs exist in remission samples, suggestive of both chemotherapy resistance and cell population poised for relapse (Jan et al. 2012; Shlush et al. 2014).

$\mathrm{CH}$ only rarely progresses to AML. Casecontrol studies from multiple independent teams have sought to better define factors that distinguish CH from pre-AML (Abelson et al. 2018; Desai et al. 2018). Desai and colleagues deeply sequenced banked peripheral blood specimens from the Women's Health Initiative (WHI) study at a median of $9.6 \mathrm{yr}$ before AML diagnosis alongside matched control participants who did not develop AML during an equivalent follow-up period. Overall, mutations were more common in pre-AML cases versus AML-free controls when present at $>1 \%$ VAF (OR: 4.86, 3.07-7.77; $\left.P=3.8 \times 10^{-13}\right)$. Particular mutation patterns conferred varying levels of risk when adjusted for age and co-mutations. Multiple mutations in DNMT3A or TET2 were more adverse than single mutations: single DNMT3A (OR: $2.11,1.19-3.75 ; P=0.011) ; 2+D N M T 3 A$ mutations (OR: 12.6, 3.02-52.92; $P<0.001$ ); single TET2 (OR: $3.29,1.38-7.83 ; P=0.005$ ); and $2+$ TET2 (OR: 69.3, 3.76-1280.7; $P<0.001$ ). The risk of AML progression for DNMT3A and TET2 mutations was also dependent on allelic fraction with $>10 \%$ VAF conferring more risk. The converse was true for mutations at any VAF $>1 \%$ in TP53 (OR: 50.9, 2.76-943.01; $P<$ 0.001 ), IDH1 or IDH2 (OR: 29.6, 1.51-582.25; $P<0.001$ ), JAK2 (OR: 5.83, 0.79-43; $P=0.042$ ), and spliceosome genes (OR: 7.72, 1.75-34.02, $P=0.002$ ). The concurrent study by Abelson and colleagues, using an independent cohort, revealed similar findings with regard to mutation-specific risks. Additionally, subsequent work by Young and colleagues, using a cohort comprised of the Nurses' Health Study and Health Professionals Follow-up Study found a similar elevated risk of AML with mutations at $\geq 1 \%$ VAF (OR: 5.4, 1.8-16.6; $P=0.003$ ) as well as elevated risk with DNMT3A R882H or R882C variants (OR: 7.3, 1.5-34.7; $P=0.01$ ) (CalvilloArgüelles et al. 2019). All studies found that pre-AML cases were devoid of FLT3 or NPM1 mutations with the exception of one case in the study by Desai and colleagues in which longitudinal follow-up at 1-yr postbaseline acquired an NPM1 mutation followed by AML diagnosis nearly a month later. Abelson and colleagues further developed a predictive model heavily dependent on high RDW as an informative predictor of AML as much as $1 \mathrm{yr}$ before diagnosis from readily available electronic health record data. However, improved sensitivity and specificity are required for a rare disease such as AML. Overall, the data from both studies suggest that, with further study and improved models, a monitoring strategy combining readily available EHR parameters, sensitive mutation testing, and perhaps other molecular parameters, can identify persons at higher risk of progression from $\mathrm{CH}$ to $\mathrm{HM}$.

\section{BYSTANDER CLONAL HEMATOPOIESIS: ACTION AT A DISTANCE}

The effects of $\mathrm{CH}$ on cancer development likely extend beyond the initial genetic hit in the twohit model of oncogenesis. Preclinical and epidemiological evidence suggests that $\mathrm{CH}$ mutations can produce a chronic inflammatory state (Cook et al. 2017; Cull et al. 2017; Fuster et al. 2017; Sano et al. 2018), which is known to be oncogenic and exert prosurvival effects outside the context of $\mathrm{CH}$ via multiple mechanisms, including NF- $\kappa \mathrm{B}$ activation (Philip et al. 2004). TET2 deficient macrophages produce elevated and prolonged expression of pro-inflammatory factors (e.g., IL-1, IL-6, TNF $\alpha$, CCL-5, CXCL9) (Zhang et al. 2015; Fuster et al. 2017; Cai et al. 2018; Sano et al. 2018). Moreover, hematopoietic cells showing TET2-driven $\mathrm{CH}$ gain a growth advantage in the presence of an inflammatory environment containing TNF (Abegunde et al. 2018). Thus, $\mathrm{CH}$ simultaneously appears to provide an advantage to affected cells under inflammatory conditions while also propagating the inflammation. Cook and colleagues evaluated human serum and found associations between $\mathrm{CH}$ mutations and inflammation, revealing elevated IL-6 with TET2-driven $\mathrm{CH}$ and elevated CCL11 with DNMT3A-driven $\mathrm{CH}$. $\mathrm{CH}$ of large clone size of $>10 \%$ presented with elevated TNF $\alpha$ (Cook et al. 2017). 
J. Kaner et al.

Consistent with this concept, studies of solid tumor and multiple myeloma patients with incidental findings of $\mathrm{CH}$ show that $\mathrm{CH}$-positive patients experience worse outcomes (Coombs et al. 2017; Mouhieddine et al. 2018). However, further studies are needed to characterize the inflammatory factors in the serum of these patients and determine if $\mathrm{CH}$-driven signaling is enabling tumor survival or whether tumor-driven inflammation is causing expansion of $\mathrm{CH}$ clones or, as is likely, an interplay of both.

\section{CLONAL HEMATOPOIESIS IS ASSOCIATED WITH ADVERSE SOLID TUMOR OUTCOMES}

Coombs and colleagues systematically evaluated the impact of $\mathrm{CH}$ in solid tumor patients using the MSK-IMPACT panel (Coombs et al. 2017). In a large analysis of $~ 9000$ individuals, $~ 25 \%$ of solid tumor patients had incidental $\mathrm{CH}$ and $4.5 \%$ harbored mutations in genes typically associated with leukemia and with VAF $\geq 10 \%$ (presumptive drivers, $\mathrm{CH}-\mathrm{PD}$ ). Importantly, $\mathrm{CH}-\mathrm{PD}$ was associated with shorter 24-mo survival: OS: 0.48 (0.40-0.57, 95\% CI) with CH-PD versus 0.54 (0.52-0.56, 95\% CI) without CH-PD. Cumulative incidence of secondary $\mathrm{HM}$ was significantly higher with $\mathrm{CH}-\mathrm{PD}$ with $3.2 \%(1.4 \%-6.2 \%)$ of patients with $\mathrm{CH}-\mathrm{PD}$ progressing to $\mathrm{HM}$ within 18 moversus $0.3 \%(0.2 \%-0.6 \%)$ of patients without $\mathrm{CH}-\mathrm{PD}(P<0.001)$. Although the prevalence of $\mathrm{CH}$ was higher than previously reported in the general population by previous studies (Jaiswal et al. 2014; Genovese et al. 2015), normalization of sequencing and analytical methodologies is needed to make an accurate comparison given the differences in depth of coverage, limits of detection, and analytics. The study also found that PPM1D and TP53 were associated with prior exposure to chemotherapy and radiotherapy, a finding similar to cohorts of patients with lymphoma and myeloma before ASCT (Abdel-Wahab et al. 2012; Husby et al. 2018; Mouhieddine et al. 2018).

\section{Clonal Hematopoiesis and Risk of Therapy- Related Myeloid Neoplasms}

The co-occurrence of $\mathrm{CH}$ with other cancers is known to result in worse outcomes in these in- dividuals and an increased risk for treatment related myeloid neoplasms (t-MNs). In a small case-control study, Takahashi and colleagues showed the prognostic impact of $\mathrm{CH}$ mutations before receiving chemotherapy or radiation treatment. The HR for development of t-MNs in those with $\mathrm{CH}$ as compared with those without $\mathrm{CH}$ was $13.7, P=0.013$. Additionally, cumulative incidence of t-MNs at $5 \mathrm{yr}$ was significantly higher in patients with $\mathrm{CH}$ (30\% [95\% CI: $16 \%-51 \%$ ] vs. $7 \%$ [95\% CI: $2 \%-21 \%$ ], $P=$ $0.016)$ (Takahashi et al. 2017). Given the universally poor outcomes that exist in those that develop t-MNs, close monitoring of blood counts and clone size in individuals with malignancies and co-existing $\mathrm{CH}$ could prove to be beneficial, although how to intervene should it become evident that a $\mathrm{t}-\mathrm{MN}$ is likely requires further investigation and should be performed as part of a clinical trial.

\section{ASSOCIATIONS BETWEEN CH AND MULTIPLE MYELOMA OUTCOMES}

Mouhieddine and colleagues evaluated the impact of $\mathrm{CH}$ mutations on multiple myeloma (MM) outcomes post-ASCT in the presence and absence of the immunomodulatory (IMiD) agents lenalidomide and pomalidomide (Mouhieddine et al. 2018). HSCs of 629 MM patients were deeply sequenced to nearly $1000 \times$ depth of coverage. Overall, having a $\mathrm{CH}$ mutation was associated with inferior OS and PFS in MM.

Importantly, the investigators found that the adverse impact of $\mathrm{CH}$ seen in $\mathrm{MM}$ patients was obviated by IMiD maintenance (lenalidomide, pomalidomide, etc.) therapy after ASCT such that OS and PFS differences were no longer significant. Although a mechanism remains to be described, one possibility is that IMiD therapy is acting via suppression of inflammatory factors normally up-regulated by CH such as TNFo, IL-6, IL-1, and IL-12 (Stahl and Zeidan 2017), thus preventing prosurvival signaling such as NF- $\mathrm{BB}$ in the myeloma cells. Given the pleiotropic effects of IMiDs, further study is required to delineate the precise mechanism. 


\section{INHERITED PREDISPOSITION TO CH}

Data suggest an inherited risk of $\mathrm{CH}$ in some cases, although this does not account for the majority of patients with $\mathrm{CH}$. Zink and colleagues showed that an SNP (rs34002450) in the telomerase reverse transcriptase (TERT) was associated with increased $\mathrm{CH}$ (OR: 1.37; $\left.P=7.4 \times 10^{-12}\right)$. In a study of 151,202 individuals with banked blood samples, Loh and colleagues showed several rare mosaic chromosomal alterations (mCA) that were associated with inherited risk for developing $\mathrm{CH}$ mutations (Loh et al. 2018).

Other groups have also shown a heritable aspect of $\mathrm{CH}$. In an analysis of 2530 women, TET2, but not DNMT3A, was shown to have a fairly high risk of heritability as a function of age, between 2.24 and 2.65 times the normal risk in women $>55 \mathrm{yr}$ and $65 \mathrm{yr}$, respectively (Buscarlet et al. 2017). Interestingly, in the allogeneic transplantation setting, matched sibling donors who were donating to a sibling with myeloid disease were more likely to have $\mathrm{CH}$ compared with those donating to a sibling with a lymphoid malignancy (19.2\% vs. $6.3 \%)$.

In addition, an analysis of several young AML patients with high mutational burden and genomic evidence of methylation damage, revealed germline mutations in $M B D 4$. It appears that loss-of-function mutations in $M B D 4$ led to inactivating mutations in DNMT3A and acquisition of other high-risk mutations such as $I D H 1$ and $I D H 2$, akin to the process by which $\mathrm{CH}$ leads to AML, albeit at an accelerated rate (Sanders et al. 2018). Methyl-binding domain 4 (MBD4) is a DNA glycosylase responsible for the removal of mispaired thymine as a function of base excision repair due to aberrant $5 \mathrm{mC}$ deamination.

\section{PRECLINICAL DATA ON MODIFICATION $\mathrm{OFCH}$}

Intervention in $\mathrm{CH}$ first requires the development of evidence-based guidelines for determining at-risk people who are destined to develop $\mathrm{CH}$-related diseases as well as data to prove that intervention/modification of $\mathrm{CH}$ is feasible and will ultimately lead to prevention of disease. Although data thus far suggest an elevated risk of AML mutations in certain genes, high allelic fraction, and multiple mutations, the risk of progression is relatively low (Genovese et al. 2014; Abelson et al. 2018; Desai et al. 2018). There have been several preclinical investigations at possible modes of intervention.

\section{TARGETING HIGH-RISK MUTATIONS IN CH}

Inhibitors of $J A K 2, I D H 1$, and $I D H 2$ are Food and Drug Administration (FDA)-approved targeted therapies with favorable safety profiles. The JAK2 inhibitor ruxolitinib is used in $J A K 2+$ myelofibrosis and has been shown to reduce symptom burden while slightly reducing the mutant allele burden (Verstovsek et al. 2012). IDH1 and IDH2 inhibitors ivosidenib and enasidenib respectively, are both approved for use in relapsed/refractory AML (Stein et al. 2017; DiNardo et al. 2018) and are currently being investigated in clinical trials for use in other $I D H 1+$ and $I D H 2+$ MPNs as well as upfront in AML in combination with induction chemotherapy and in MDS (NCT03839771, NCT035 15512, NCT03471260). There are, currently, no clinical trials investigating the safety or efficacy of targeting either $J A K 2, I D H 1$, or $I D H 2$ in the context of $\mathrm{CH}$. Given the greater tendency of IDH1/2 and JAK2 mutations in $\mathrm{CH}$ to progress to AML (Desai et al. 2018), targeting these mutations with already approved drugs needs requires investigation, most likely in the context of patients showing abnormal hematological parameters.

\section{Vitamin C to Compensate for TET2 Haploinsufficiency}

TET2 mutations exert their effects through altered methylation patterns in affected cells, ultimately leading to $\mathrm{CH}$ and possibly MDS or AML. Restoration of normal TET2 enzymatic function was hypothesized to halt or reverse this process. This hypothesis was tested in a TET2 knockdown mouse model (Cimmino et al. 2017). Reversible TET2 knockdown recapitulated the effects of TET2 deletion, leading to 
J. Kaner et al.

aberrant HSC self-renewal and disease development. In this same mouse model, exogenous vitamin $\mathrm{C}$ was shown to promote restoration of normal TET2 enzymatic function by increasing DNA demethylation in embryonic stem cells and induced pluripotent stem cells leading to enhanced 5-hydroxymethylcytosine (5-hmC) levels (Cimmino et al. 2017). Studies suggesting that this may be true in humans are lacking.

\section{Low Glucose and Metformin}

Tet 2 protein is destabilized by high glucose levels, a process mediated by the inhibition of AMP-activated protein kinase (AMPK)-dependent phosphorylation of TET2 at serine-99, leading to marked reduction of 5-hydroxymethycytosine levels (Wu et al. 2018). This effect was rescued by metformin in mouse models. Thus, loss of TET2 enzymatic function via protein destabilization has the potential exacerbate the loss of TET2 function observed in TET2driven $\mathrm{CH}$, thereby potentiating the effects of $\mathrm{CH}$. Interestingly, large epidemiological analyses have suggested that diabetes is linked to an increased risk for cancer, with type 2 diabetes conferring a 20\% increase in HM risk (Gallagher and LeRoith 2015; Lauby-Secretan et al. 2016). Thus, the complex interplay of diabetes and cancer requires further study in the context hematopoiesis.

\section{Inhibition of Inflammation}

$\mathrm{CH}$ is itself pro-inflammatory and simultaneously confers a fitness advantage under pro-inflammatory conditions (Cook et al. 2017; Cull et al. 2017; Abegunde et al. 2018). Thus, intervening in this pattern of runaway inflammation may mitigate the effects of $\mathrm{CH}$. In CVD, it has already been shown that IL-1 blockade with canakunimab shows improved responsiveness in patients with TET2-driven $\mathrm{CH}$ (Svensson et al. 2018). In an unrelated preclinical study, Cai and colleagues exposed TET2 knockout (TET2-KO) mice to inflammatory stress, leading to consistently higher levels of IL- 6 being seen in these mice. IL- 6 was found to result in hyperactivation of the SHP2-STAT3 signaling axis and increased expression of anti-apoptotic long noncoding DNA, Morrbid (Cai et al. 2018). Inhibition of IL-6 signaling via knockout of Morrbid or via small-molecule inhibition on the SHP2-STAT3 pathway with SHP099 or E330 impaired clonal expansion of TET2 KO HSPCs. Thus, inhibition of IL-6, IL-1, or other pro-inflammatory cytokines using either directed monoclonal antibody or anti-inflammatory small molecules may have the potential for modification of $\mathrm{CH}$ and/or mitigating the bystander effects of $\mathrm{CH}$ mediated through inflammatory signaling.

\section{CLINICAL FOLLOW-UP OF PATIENTS WITH CLONAL HEMATOPOIESIS}

$\mathrm{CH}$ is being increasingly detected in patients during workup of cytopenias and as part of tumor genomic reports for both solid and hematologic malignancies. As data on the effect of $\mathrm{CH}$ accumulate, there is obvious clinical interest in managing the risks associated with $\mathrm{CH}$. Because $\mathrm{CH}$ is associated with increased cardiovascular mortality, the presentation of $\mathrm{CH}$ - particularly mutations in DNMT3A and TET2 at high VAFs and/or multiple mutations-should prompt a referral to cardiology for cardiovascular risk assessment and management. The presence of high-risk $\mathrm{CH}$ in patients with malignancy (TP53, PPM1D, clonal complexity, high VAF $\mathrm{CH}$ defined as $>10 \%$ VAF, DNMT3A-R882) may influence decisions regarding the use of radiation or chemotherapy in some cases. For example, the presence of these high-risk mutations could prompt a discussion in the setting of autologous transplant if there are alternative therapies available. Regardless, the risks and benefits of either approach needs to be discussed with patients. In the absence of data to support repeat mutation testing, patients with $\mathrm{CH}$ should be followed with blood counts only as standard of care and repeat testing of mutations should only be considered as part of a clinical trial or in the context new or worsening cytopenias.

\section{CONCLUDING REMARKS}

The prevalence of $\mathrm{CH}$ is more common than originally put forward given recent findings 
Clonal Hematopoiesis and Premalignant Diseases

from high-depth, high-sensitivity sequencing studies (Young et al. 2016; Coombs et al. 2017; Abelson et al. 2018; Desai et al. 2018; Calvillo-Argüelles et al. 2019; Young et al. 2019). Current evidence suggests mutations of $>1 \%$ VAF can be of clinical relevance for progression to malignancy (Abelson et al. 2018; Desai et al. 2018; Young et al. 2019). Standardization of methodologies and development of evidence-based guidelines are required to determine detection limits and parameters for identification of clinically significant $\mathrm{CH}$ mutations. In addition to providing founding genetic lesions for hematologic cancers, $\mathrm{CH}$ is a predictor of adverse risk in existing cancers ranging from solid tumors to multiple myeloma (Coombs et al. 2017; Mouhieddine et al. 2018), suggestive of a $\mathrm{CH}$-driven bystander influence. Further studies are required to ascertain whether this possible bystander influence is mediated through inflammation or by other mechanisms. $\mathrm{CH}$ further confers elevated susceptibility to secondary therapy-related HMs (Coombs et al. 2017; Takahashi et al. 2017) and thus potentially impact guidelines for use of radiotherapy and/or chemotherapy in cancer patients who present with $\mathrm{CH}$ as a comorbidity.

Preclinical data suggest that $\mathrm{CH}$ may be intervened on, although any intervention would require considerable risk-benefit analysis. Preliminary evidence suggests that vitamin C, metformin, and anti-inflammatory agents may represent possible modifying interventions in $\mathrm{CH}$. On further preclinical evaluation and confirmation in $\mathrm{CH}$-focused studies, observational trials may be warranted in humans to test the impact of potential interventions on $\mathrm{CH}$ clones - preferably in patients already exposed to these drugs. Regardless, screening of $\mathrm{CH}$ in individuals at high risk of myeloid neoplasms could prove to beneficial right now in cancer patients undergoing genotoxic therapy. Overall, management guidelines for $\mathrm{CH}$ are urgently needed for both HM and CVD risk. Thus, formation of an international advisory committee of clinical experts, precision medicine specialists, and epidemiological and laboratory medicine experts is required.

\section{ACKNOWLEDGMENTS}

We are grateful to members of the Hassane laboratory and Guzman laboratory for useful feedback and discussions. This work is supported in part by Leukemia Fighters and the Sandra and Edward Meyer Cancer Center. We are further thankful to the Caryl \& Israel Englander Institute for Precision Medicine for supporting our precision medicine efforts in $\mathrm{CH}$ risk prediction and prevention.

\section{REFERENCES}

Abdel-Wahab O, Adli M, LaFave LM, Gao J, Hricik T, Shih AH, Pandey S, Patel JP, Chung YR, Koche R, et al. 2012. ASXL1 mutations promote myeloid transformation through loss of PRC2-mediated gene repression. Cancer Cell 22: 180-193. doi:10.1016/j.ccr.2012.06.032

Abegunde SO, Buckstein R, Wells RA, Rauh MJ. 2018. An inflammatory environment containing TNF $\alpha$ favors Tet2-mutant clonal hematopoiesis. Exp Hematol 59: 60-65. doi:10.1016/j.exphem.2017.11.002

Abelson S, Collord G, Ng SWK, Weissbrod O, Mendelson Cohen N, Niemeyer E, Barda N, Zuzarte PC, Heisler L, Sundaravadanam Y, et al. 2018. Prediction of acute myeloid leukaemia risk in healthy individuals. Nature 559: 400-404. doi:10.1038/s41586-018-0317-6

Baba Y, Saito B, Shimada S, Sasaki Y, Murai S, Abe M, Fujiwara S, Arai N, Kawaguchi Y, Kabasawa N, et al. 2018. Association of red cell distribution width with clinical outcomes in myelodysplastic syndrome. Leuk Res 67: 56-59. doi:10.1016/j.leukres.2018.02.004

Blokzijl F, de Ligt J, Jager M, Sasselli V, Roerink S, Sasaki N, Huch M, Boymans S, Kuijk E, Prins P, et al. 2016. Tissuespecific mutation accumulation in human adult stem cells during life. Nature 538: 260-264. doi:10.1038/na ture 19768

Bowman RL, Busque L, Levine RL. 2018. Clonal hematopoiesis and evolution to hematopoietic malignancies. Cell Stem Cell 22: 157-170. doi:10.1016/j.stem.2018.01.011

Buscarlet M, Provost S, Zada YF, Barhdadi A, Bourgoin V, Lépine G, Mollica L, Szuber N, Dubé MP, Busque L. 2017. DNMT3A and TET2 dominate clonal hematopoiesis and demonstrate benign phenotypes and different genetic predispositions. Blood 130: 753-762. doi:10.1182/ blood-2017-04-777029

Busque L, Mio R, Mattioli J, Brais E, Blais N, Lalonde Y, Maragh M, Gilliland DG. 1996. Nonrandom X-inactivation patterns in normal females: Lyonization ratios vary with age. Blood 88: 59-65.

Busque L, Patel JP, Figueroa ME, Vasanthakumar A, Provost S, Hamilou Z, Mollica L, Li J, Viale A, Heguy A, et al. 2012. Recurrent somatic TET2 mutations in normal elderly individuals with clonal hematopoiesis. Nat Genet 44: 1179-1181. doi:10.1038/ng.2413

Cai Z, Kotzin JJ, Ramdas B, Chen S, Nelanuthala S, Palam LR, Pandey R, Mali RS, Liu Y, Kelley MR, et al. 2018 Inhibition of inflammatory signaling in Tet 2 mutant pre- 
J. Kaner et al.

leukemic cells mitigates stress-induced abnormalities and clonal hematopoiesis. Cell Stem Cell 23: 833-849 e835. doi:10.1016/j.stem.2018.10.013

Calvillo-Argüelles O, Jaiswal S, Shlush LI, Moslehi JJ, Schimmer A, Barac A, Thavendiranathan P. 2019. Connections between clonal hematopoiesis, cardiovascular disease, and cancer: A review. JAMA Cardiol 4: 380387. doi:10.1001/jamacardio.2019.0302

Catlin SN, Busque L, Gale RE, Guttorp P, Abkowitz JL. 2011. The replication rate of human hematopoietic stem cells in vivo. Blood 117: 4460-4466. doi:10.1182/blood-2010-08303537

Chou WC, Chou SC, Liu CY, Chen CY, Hou HA, Kuo YY, Lee MC, Ko BS, Tang JL, Yao M, et al. 2011. TET2 mutation is an unfavorable prognostic factor in acute myeloid leukemia patients with intermediate-risk cytogenetics. Blood 118: 3803-3810. doi:10.1182/blood-2011-02339747

Cimmino L, Dolgalev I, Wang Y, Yoshimi A, Martin GH, Wang J, Ng V, Xia B, Witkowski MT, Mitchell-Flack M, et al. 2017. Restoration of TET2 function blocks aberrant self-renewal and leukemia progression. Cell 170: 10791095.e20. doi:10.1016/j.cell.2017.07.032

Cook EK, Izukawa T, Young S, Rosen G, Jamali M, Snetsinger B, Johnson D, Bain E, Hilland J, Buckstein J, et al. 2017. Feeding the fire: The comorbid and inflammatory backdrop of clonal hematopoiesis of indeterminate potential (CHIP) by mutation subtype. Blood 130: 426 .

Coombs CC, Zehir A, Devlin SM, Kishtagari A, Syed A, Jonsson P, Hyman DM, Solit DB, Robson ME, Baselga J, et al. 2017. Therapy-related clonal hematopoiesis in patients with non-hematologic cancers is common and associated with adverse clinical outcomes. Cell Stem Cell 21: 374-382.e4. doi:10.1016/j.stem.2017.07.010

Cull AH, Snetsinger B, Buckstein R, Wells RA, Rauh MJ. 2017. Tet2 restrains inflammatory gene expression in macrophages. Exp Hematol 55: 56-70.e13. doi:10.1016/j exphem.2017.08.001

De S. 2011. Somatic mosaicism in healthy human tissues. Trends Genet 27: 217-223. doi:10.1016/j.tig.2011.03.002

Delhommeau F, Dupont S, Della Valle V, James C, Trannoy S, Massé A, Kosmider O, Le Couedic JP, Robert F, Alberdi A, et al. 2009. Mutation in TET2 in myeloid cancers. $N$ Engl J Med 360: 2289-2301. doi:10.1056/NEJ Moa0810069

Desai P, Mencia-Trinchant N, Savenkov O, Simon MS, Cheang G, Lee S, Samuel M, Ritchie EK, Guzman ML, Ballman KV, et al. 2018. Somatic mutations precede acute myeloid leukemia years before diagnosis. Nat Med 24: 1015-1023. doi:10.1038/s41591-018-0081-z

DiNardo CD, Stein EM, de Botton S, Roboz GJ, Altman JK, Mims AS, Swords R, Collins RH, Mannis GN, Pollyea DA et al. 2018. Durable remissions with ivosidenib in IDH1mutated relapsed or refractory AML. N Engl J Med 378: 2386-2398. doi:10.1056/NEJMoa1716984

Fuster JJ, MacLauchlan S, Zuriaga MA, Polackal MN, Ostriker AC, Chakraborty R, Wu CL, Sano S, Muralidharan S, Rius C, et al. 2017. Clonal hematopoiesis associated with TET2 deficiency accelerates atherosclerosis development in mice. Science 355: 842-847. doi:10.1126/science .aag1381
Gale RE, Wheadon H, Linch DC. 1991. X-chromosome inactivation patterns using HPRT and PGK polymorphisms in haematologically normal and post-chemotherapy females. Br J Haematol 79: 193-197. doi:10.1111/j.13652141.1991.tb04521.x

Gallagher EJ, LeRoith D. 2015. Obesity and diabetes: The increased risk of cancer and cancer-related mortality. Physiol Rev 95: 727-748. doi:10.1152/physrev.00030.2014

Genovese G, Kähler AK, Handsaker RE, Lindberg J, Rose SA, Bakhoum SF, Chambert K, Mick E, Neale BM, Fromer M, et al. 2014. Clonal hematopoiesis and blood-cancer risk inferred from blood DNA sequence. N Engl J Med 371: 2477-2487. doi:10.1056/NEJMoa1409405

Genovese G, Jaiswal S, Ebert BL, McCarroll SA. 2015. Clonal hematopoiesis and blood-cancer risk. N Engl J Med 372: 1071-1072. doi:10.1056/NEJMc1500684

Hall J, Al Hafidh J, Balmert E, Dabbas B, Vaupel C, El Hader C, McGinniss M, Beruti S, Bejar R. 2014. Somatic mutations indicative of clonal hematopoiesis are present in a large fraction of cytopenic patients who lack diagnostic evidence of MDS. Blood 124: 3272.

Heuser M, Thol F, Ganser A. 2016. Clonal hematopoiesis of indeterminate potential. Dtsch Arztebl Int 113: 317-322.

Husby S, Francesco F, Nielsen C, Sorensen B, Baech J, Hansen JW, Gonzalez GGR, Arboe B, Andersen LP, Hastrup EK, et al. 2018. Clinical impact of clonal hematopoiesis after autologous stem cell transplantation for lymphoma: A National Population-Based Cohort Study. Blood 132: 607.

Jaiswal S, Fontanillas P, Flannick J, Manning A, Grauman PV, Mar BG, Lindsley RC, Mermel CH, Burtt N, Chavez A, et al. 2014. Age-related clonal hematopoiesis associated with adverse outcomes. N Engl J Med 371: 2488-2498. doi:10.1056/NEJMoa1408617

Jan M, Snyder TM, Corces-Zimmerman MR, Vyas P, Weissman IL, Quake SR, Majeti R. 2012. Clonal evolution of pre-leukemic hematopoietic stem cells precedes human acute myeloid leukemia. Sci Transl Med 4: 149ra118.

Kim SJ, Zhao H, Hardikar S, Singh AK, Goodell MA, Chen T. 2013. A DNMT3A mutation common in AML exhibits dominant-negative effects in murine ES cells. Blood 122: 4086-4089. doi:10.1182/blood-2013-02-483487

Knudson AG Jr. 1971. Mutation and cancer: Statistical study of retinoblastoma. Proc Natl Acad Sci 68: 820-823. doi:10 $.1073 /$ pnas.68.4.820

Kwok B, Reddy P, Lin KM, Flamholz R, Yung AN, Dabbas B, McGinniss M, Nahas S, Kines J, Xu Y. 2014. Next-generation sequencing (NGS)-based profiling of idiopathic cytopenia of undetermined significance (ICUS) identifies a subset of patients with genomic similarities to lower-risk myelodysplastic syndrome (MDS). Blood 124: 166.

Kyle RA, Therneau TM, Rajkumar SV, Offord JR, Larson DR, Plevak MF, Melton LJ III. 2002. A long-term study of prognosis in monoclonal gammopathy of undetermined significance. $N$ Engl J Med 346: 564-569. doi:10.1056/ NEJMoa01133202

Lauby-Secretan B, Scoccianti C, Loomis D, Grosse Y, Bianchini F, Straif K, International Agency for Research on Cancer Handbook Working Group. 2016. Body fatness and cancer-Viewpoint of the IARC Working Group. $N$ Engl J Med 375: 794-798. doi:10.1056/NEJMsr1606602 
Loh PR, Genovese G, Handsaker RE, Finucane HK, Reshef YA, Palamara PF, Birmann BM, Talkowski ME, Bakhoum SF, McCarroll SA, et al. 2018. Insights into clonal haematopoiesis from 8,342 mosaic chromosomal alterations. Nature 559: 350-355. doi:10.1038/s41586-018-0321-x

Lyon MF. 1961. Gene action in the X-chromosome of the mouse (Mus musculus L.). Nature 190: 372-373. doi:10 $.1038 / 190372 \mathrm{a} 0$

Madzo J, Liu H, Rodriguez A, Vasanthakumar A, Sundaravel S, Caces DBD, Looney TJ, Zhang L, Lepore JB, Macrae T, et al. 2014. Hydroxymethylation at gene regulatory regions directs stem/early progenitor cell commitment during erythropoiesis. Cell Rep 6: 231-244. doi:10.1016/j celrep.2013.11.044

Martincorena I, Raine KM, Gerstung M, Dawson KJ, Haase K, Van Loo P, Davies H, Stratton MR, Campbell PJ. 2017. Universal patterns of selection in cancer and somatic tissues. Cell 171: 1029-1041.e21. doi:10.1016/j.cell.2017.09 .042

Meisel M, Hinterleitner R, Pacis A, Chen L, Earley ZM, Mayassi T, Pierre JF, Ernest JD, Galipeau HJ, Thuille N, et al. 2018. Microbial signals drive pre-leukaemic myeloproliferation in a Tet2-deficient host. Nature 557: 580584. doi:10.1038/s41586-018-0125-Z

Moran-Crusio K, Reavie L, Shih A, Abdel-Wahab O, Ndiaye-Lobry D, Lobry C, Figueroa ME, Vasanthakumar A, Patel J, Zhao X, et al. 2011. Tet2 loss leads to increased hematopoietic stem cell self-renewal and myeloid transformation. Cancer Cell 20: 11-24. doi:10.1016/j.ccr.2011 .06 .001

Mouhieddine TH, Park J, Redd RA, Gibson CJ, Manier S, Nassar AH, Capelletti M, Huynh D, Bustoros M, Sklavenitis-Pistofidis R, et al. 2018. The role of clonal hematopoiesis of indeterminate potential (CHIP) in multiple myeloma: Immunomodulator maintenance post autologous stem cell transplant (ASCT) predicts better outcome. Blood 132: 749.

Philip M, Rowley DA, Schreiber H. 2004. Inflammation as a tumor promoter in cancer induction. Semin Cancer Bio 14: 433-439. doi:10.1016/j.semcancer.2004.06.006

Rasmussen KD, Jia G, Johansen JV, Pedersen MT, Rapin N, Bagger FO, Porse BT, Bernard OA, Christensen J, Helin K. 2015. Loss of TET2 in hematopoietic cells leads to DNA hypermethylation of active enhancers and induction of leukemogenesis. Genes Dev 29: 910-922. doi:10.1101/gad .260174 .115

Rawstron AC, Bennett FL, O'Connor SJ, Kwok M, Fenton JA, Plummer M, de Tute R, Owen RG, Richards SJ, Jack AS, et al. 2008. Monoclonal B-cell lymphocytosis and chronic lymphocytic leukemia. N Engl J Med 359: 575 583. doi:10.1056/NEJMoa075290

Sanders MA, Chew E, Flensburg C, Zeilemaker A, Miller SE, al Hinai AS, Bajel A, Luiken B, Rijken M, McLennan T, et al. 2018. MBD4 guards against methylation damage and germ line deficiency predisposes to clonal hematopoiesis and early-onset AML. Blood 132: 1526-1534. doi:10 .1182/blood-2018-05-852566

Sano S, Wang Y, Walsh K. 2018. Clonal hematopoiesis and its impact on cardiovascular disease. Circ J 83: 2-11. doi:10.1253/circj.CJ-18-0871

Shih AH, Jiang Y, Meydan C, Shank K, Pandey S, Barreyro L, Antony-Debre I, Viale A, Socci N, Sun Y, et al. 2015.
Clonal Hematopoiesis and Premalignant Diseases

Mutational cooperativity linked to combinatorial epigenetic gain of function in acute myeloid leukemia. Cancer Cell 27: 502-515. doi:10.1016/j.ccell.2015.03.009

Shin HT, Choi YL, Yun JW, Kim NKD, Kim SY, Jeon HJ, Nam JY, Lee C, Ryu D, Kim SC, et al. 2017. Prevalence and detection of low-allele-fraction variants in clinical cancer samples. Nat Commun 8: 1377. doi:10.1038/s41467-01701470-y

Shlush LI, Zandi S, Mitchell A, Chen WC, Brandwein JM, Gupta V, Kennedy JA, Schimmer AD, Schuh AC, Yee $\mathrm{KW}$, et al. 2014. Identification of pre-leukaemic haematopoietic stem cells in acute leukaemia. Nature 506: 328333. doi: $10.1038 /$ nature 13038

Stahl M, Zeidan AM. 2017. Lenalidomide use in myelodysplastic syndromes: Insights into the biologic mechanisms and clinical applications. Cancer 123: 1703-1713. doi:10 .1002/cncr.30585

Steensma DP. 2012. Dysplasia has a differential diagnosis: Distinguishing genuine myelodysplastic syndromes (MDS) from mimics, imitators, copycats and impostors. Curr Hematol Malig Rep 7: 310-320. doi:10.1007/s11899012-0140-3

Steensma DP, Bejar R, Jaiswal S, Lindsley RC, Sekeres MA Hasserjian RP, Ebert BL. 2015. Clonal hematopoiesis of indeterminate potential and its distinction from myelodysplastic syndromes. Blood 126: 9-16. doi:10.1182/ blood-2015-03-631747

Stein EM, DiNardo CD, Pollyea DA, Fathi AT, Roboz GJ, Altman JK, Stone RM, DeAngelo DJ, Levine RL, Flinn IW, et al. 2017. Enasidenib in mutant IDH2 relapsed or refractory acute myeloid leukemia. Blood 130: 722-731. doi:10.1182/blood-2017-04-779405

Svensson EC, Madar A, Campbell CD, He Y, Sultan M, Healey ML, D'Aco K, Fernandez A, Wache-Mainer C, Ridker PM, et al. 2018. TET2-driven clonal hematopoiesis predicts enhanced response to canakinumab in the CANTOS Trial: An exploratory analysis. Circulation 138: A15111.

Takahashi K, Wang F, Kantarjian H, Doss D, Khanna K, Thompson E, Zhao L, Patel K, Neelapu S, Gumbs C, et al. 2017. Preleukaemic clonal haemopoiesis and risk of therapy-related myeloid neoplasms: A case-control study. Lancet Oncol 18: 100-111. doi:10.1016/S1470-2045(16) 30626-X

Tiacci E, Venanzi A, Ascani S, Marra A, Cardinali V, Martino G, Codoni V, Schiavoni G, Martelli MP, Falini B. 2018. High-risk clonal hematopoiesis as the origin of AITL and NPM1-mutated AML. N Engl J Med 379: 981-984. doi:10.1056/NEJMc1806413

Vattathil S, Scheet P. 2016. Extensive hidden genomic mosaicism revealed in normal tissue. Am J Hum Genet 98: 571-578. doi:10.1016/j.ajhg.2016.02.003

Verstovsek S, Mesa RA, Gotlib J, Levy RS, Gupta V, DiPersio JF, Catalano JV, Deininger M, Miller C, Silver RT, et al. 2012. A double-blind, placebo-controlled trial of ruxolitinib for myelofibrosis. N Engl J Med 366: 799-807. doi:10 1056/NEJMoa1110557

Vilkki S, Tsao JL, Loukola A, Poyhonen M, Vierimaa O, Herva R, Aaltonen LA, Shibata D. 2001. Extensive somatic microsatellite mutations in normal human tissue. Cancer Res 61: 4541-4544. 
J. Kaner et al.

Welch JS, Ley TJ, Link DC, Miller CA, Larson DE, Koboldt DC, Wartman LD, Lamprecht TL, Liu F, Xia J, et al. 2012 The origin and evolution of mutations in acute myeloid leukemia. Cell 150: 264-278. doi:10.1016/j.cell.2012.06.023

Wild CP. 2005. Complementing the genome with an "exposome": The outstanding challenge of environmental exposure measurement in molecular epidemiology. Cancer Epidemiol Biomarkers Prev 14: 1847-1850. doi:10.1158/ 1055-9965.EPI-05-0456

Wimazal F, Fonatsch C, Thalhammer R, Schwarzinger I Müllauer L, Sperr WR, Bennett JM, Valent P. 2007. Idiopathic cytopenia of undetermined significance (ICUS) versus low risk MDS: The diagnostic interface. Leuk Res 31: 1461-1468. doi:10.1016/j.leukres.2007.03.015

Wu X, Bekker-Jensen IH, Christensen J, Rasmussen KD, Sidoli S, Qi Y, Kong Y, Wang X, Cui Y, Xiao Z, et al. 2015. Tumor suppressor ASXL1 is essential for the activation of $I N K 4 B$ expression in response to oncogene activity and anti-proliferative signals. Cell Res 25: 12051218. doi:10.1038/cr.2015.121

Wu D, Hu D, Chen H, Shi G, Fetahu IS, Wu F, Rabidou K, Fang R, Tan L, Xu S, et al. 2018. Glucose-regulated phosphorylation of TET2 by AMPK reveals a pathway linking diabetes to cancer. Nature 559: 637-641. doi:10.1038/ s41586-018-0350-5

Xie M, Lu C, Wang J, McLellan MD, Johnson KJ, Wendl MC, McMichael JF, Schmidt HK, Yellapantula V, Miller CA, et al. 2014. Age-related mutations associated with clonal hematopoietic expansion and malignancies. Nat Med 20: 1472-1478. doi:10.1038/nm.3733
Yoshizato T, Dumitriu B, Hosokawa K, Makishima H, Yoshida K, Townsley D, Sato-Otsubo A, Sato Y, Liu D, Suzuki $\mathrm{H}$, et al. 2015. Somatic mutations and clonal hematopoiesis in aplastic anemia. $N$ Engl J Med 373: 35-47. doi:10 .1056/NEJMoa1414799

Young AL, Challen GA, Birmann BM, Druley TE. 2016 Clonal haematopoiesis harbouring AML-associated mutations is ubiquitous in healthy adults. Nat Commun 7: 12484. doi:10.1038/ncomms12484

Young AL, Tong RS, Birmann BM, Druley TE. 2019. Clonal haematopoiesis and risk of acute myeloid leukemia. Haematologica doi: 10.3324/haematol.2018.215269.

Zhang Q, Zhao K, Shen Q, Han Y, Gu Y, Li X, Zhao D, Liu Y, Wang C, Zhang X, et al. 2015. Tet2 is required to resolve inflammation by recruiting Hdac2 to specifically repress IL-6. Nature 525: 389-393. doi:10.1038/na ture 15252

Zink F, Stacey SN, Norddahl GL, Frigge ML, Magnusson OT, Jonsdottir I, Thorgeirsson TE, Sigurdsson A, Gudjonsson SA, Gudmundsson J, et al. 2017. Clonal hematopoiesis, with and without candidate driver mutations, is common in the elderly. Blood 130: 742-752. doi:10.1182/blood2017-02-769869

Zurauskaite G, Meier M, Voegeli A, Koch D, Haubitz S, Kutz A, Bernasconi L, Huber A, Bargetzi M, Mueller B, et al. 2018. Biological pathways underlying the association of red cell distribution width and adverse clinical outcome: Results of a prospective cohort study. PLoS One 13: e0191280. doi:10.1371/journal.pone.0191280 


\section{$\&_{\mathrm{CSH}}^{\infty} \&$ Cold Spring Harbor

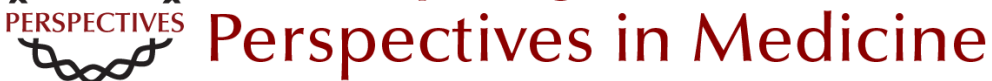

\section{Clonal Hematopoiesis and Premalignant Diseases}

Justin Kaner, Pinkal Desai, Nuria Mencia-Trinchant, Monica L. Guzman, Gail J. Roboz and Duane C. Hassane

Cold Spring Harb Perspect Med 2020; doi: 10.1101/cshperspect.a035675 originally published online October 15, 2019

Subject Collection Leukemia and Lymphoma: Molecular and Therapeutic Insights

Oncogenic Mechanisms and Therapeutic

Targeting of Metabolism in Leukemia and Lymphoma

Maximilian Stahl, Zachary D. Epstein-Peterson and Andrew M. Intlekofer

Non-Hodgkin Lymphomas: Malignancies Arising from Mature B Cells Jennifer Shingleton, Jie Wang, Carolyn Baloh, et al.

MAP-Kinase-Driven Hematopoietic Neoplasms: A Decade of Progress in the Molecular Age Rikhia Chakraborty, Omar Abdel-Wahab and Benjamin H. Durham

Mouse Models in the Study of Mature B-Cell Malignancies Laura Pasqualucci and Ulf Klein

Mouse Models of Myeloid Malignancies Faisal Basheer and George Vassiliou

Epigenetic Mechanisms in Leukemias and Lymphomas

Cihangir Duy, Wendy Béguelin and Ari Melnick

The Biology of B-Progenitor Acute Lymphoblastic Leukemia

Kathryn G. Roberts and Charles G. Mullighan

RNA Regulators in Leukemia and Lymphoma Camila Prieto and Michael G. Kharas
Biological and Translational Considerations regarding the Recent Therapeutic Successes and Upcoming Challenges for Multiple Myeloma Constantine S. Mitsiades

Biology and Molecular Pathogenesis of Mature

T-Cell Lymphomas José R. Cortés and Teresa Palomero

The Role of Somatic Mutations in Acute Myeloid Leukemia Pathogenesis Ashwin Kishtagari and Ross L. Levine

Chronic Lymphocytic Leukemia Nicholas Chiorazzi, Shih-Shih Chen and Kanti R. Rai

Normal Hematopoiesis Is a Balancing Act of

Self-Renewal and Regeneration Oakley C. Olson, Yoon-A Kang and Emmanuelle Passegué

Impact of Genetics on Mature Lymphoid

Leukemias and Lymphomas Nathanael G. Bailey and Kojo S.J. Elenitoba-Johnson

Epidemiology and Etiology of Leukemia and Lymphoma Jordan A. Baeker Bispo, Paulo S. Pinheiro and Erin K. Kobetz

Clonal Hematopoiesis and Premalignant Diseases Justin Kaner, Pinkal Desai, Nuria Mencia-Trinchant, et al.

For additional articles in this collection, see http://perspectivesinmedicine.cshlp.org/cgi/collection/ 